\title{
Mental Health, Physical Symptoms and Biomarkers of Stress during Prolonged Exposure to Antarctica's Extreme Environment
}

Candice A. Alfano ${ }^{1,2}$, Joanne L. Bower ${ }^{3}$, Christopher Connaboy ${ }^{4}$, Nadia H. Agha ${ }^{5}$, Forrest L. Baker $^{6}$, Kyle A. Smith ${ }^{6}$, Christine J. So ${ }^{1} \&$ Richard J. Simpson $6,7,8$

1. Department of Psychology, University of Houston, Houston, TX

2. Health Research Institute, University of Houston, Houston, TX

3. School of Psychology, University of East Anglia, Norwich, U.K.

4. Neuromuscular Research Laboratory, Department of Sports Medicine and Nutrition, University of Pittsburgh, Pittsburgh, PA

5. Department of Molecular Physiology and Biophysics, Baylor College of Medicine, Houston, TX

6. Department of Nutritional Sciences, University of Arizona, Tucson, AZ

7. Department of Pediatrics, University of Arizona, Tucson, AZ

8. Department of Immunobiology, University of Arizona, Tucson, AZ

Corresponding Author: Candice A. Alfano, PhD, Department of Psychology, University of Houston, Houston TX, 77204, USA. caalfano@uh.edu 


\begin{abstract}
The Antarctic environment is characterized by many of the same extreme stressors as longduration space flight (LDSE), thereby providing a useful earth-based analog for examining changes in and predictors of mental health over time. At coastal $(n=88)$ and inland $(n=22)$ Antarctic stations we tracked mental health symptoms across a nine-month period including winter-over using the Mental Health Checklist (MHCL; Bower et al., 2019). Our monthly assessment battery also examined changes in physical complaints, biomarkers of stress, and the use of different emotion regulation strategies. MHCL positive adaptation scores showed linear decreases whereas MHCL poor self-regulation scores and severity of physical symptoms increased across the study period. During-mission use of emotion regulation strategies and dehydroepiandrosterone (DHEA) levels predicted end-of-study MHCL scores, whereas traitbased psychological measures collected at the start of the mission showed little predictive utility. Results suggest that interventions and counter measures aimed at enhancing positive affect/emotion during prolonged exposure to extreme environments may be useful in reducing psychological risk.
\end{abstract}

Keywords: Antarctica; emotion regulation; mental health; physical symptoms; space flight 


\section{Introduction}

Adverse psychological reactions are recognized among the most serious risks posed to crew members and mission success during space flight (Alfano et al., 2018; Slack et. al., 2009). Selection methods and counter measures help to reduce such risk, but even the most competent and highly-skilled individuals are susceptible to adaptation problems within extreme environments. While the reported incidence of psychological crises occurring during previous missions is notably low (Gushin et al., 1993; Institute of Medicine, 2001; Otto, 2007), longduration space exploration (LDSE) such as a Mars mission will significantly extend astronauts' exposure to a range of stressors including extreme confinement and social isolation, microgravity, monotony of environmental stimuli, delays in communication, and limited privacy. A convergence of such extreme stressors is likely to produce a range of symptoms, but surprisingly little is known about the types of psychological reactions most likely to occur in isolated, confined, extreme (ICE) environments.

The Antarctic is regarded as an ideal analog for space because its extreme environment is characterized by numerous stressors that mirror those associated with extended-duration space flight. In addition to small crews and limited communication during Antarctic winter months, the environment offers little sensory stimulation and extended periods of darkness and harsh weather conditions restrict outdoor activity. Evacuation is difficult if not impossible. Evacuation is difficult if not impossible. Several classifications of psychological maladjustment have been proposed over the years to facilitate identification and early intervention in polar settings (Cazes et al., 1989; Gunderson, 1966; Strange \& Klein, 1974) but none have received wide-spread adoption. As a result, an array of measures, constructs and symptoms have been examined, most often with a central focus on negative mood (Alfano et al., 2018). Although several 
investigations have reported overall low rates of negative mood among polar expedition and station crews (Kahn \& Leon, 1994; Palinkas \& Houseal, 2000; Weiss et al., 2000; Xu et al., 2003), a recent meta-analysis of data from 21 studies reveals negative mood to fluctuate considerably across the course of Antarctic winter-over (Hawkes \& Norris, 2017). Likewise, extended Antarctic stays also negatively impact positive emotional states (Ehmann, Altbäcker, \& Balázs, 2018) and coping (Sandal, van deVijver \& Smith, 2018) over time. These results make clear a need to assess psychological functioning among polar crews repeatedly across multiple time points using a broad framework for understanding psychological adaptation in ICE environments.

Recently, our group developed a self-report measure of psychological reactions for use in ICE environments, the Mental Health Checklist (MHCL; Bower et al., 2019). Exploratory and confirmatory factor analyses of the original questionnaire in two community samples produced a 23-item measure with three reliable subscales measuring positive adaptation, poor selfregulation, and anxious apprehension. Reliability and convergent validity of the MHCL subscales were further demonstrated in a sample of $110 \mathrm{crew}$ members shortly after arrival at one of two Antarctic stations. In the current study, we examined monthly changes in these subscales in the same Antarctic cohort over the course of a winter season, as well as the extent to which several relevant, trait-based psychological constructs assessed at baseline (i.e., distress tolerance, anxiety sensitivity, and emotion dysregulation) might serve to predict end of study MHCL scores.

In addition, because emotional reactions in ICE environments might be less prognostic of mental health risk than the degree to which they can be effectively managed by the individual, we collected monthly reports of strategies used to regulate emotions. In contrast to a focus on 
'coping' which is concerned with the reduction of negative states, emotion regulation refers to the heterogeneous set of actions that influence what emotions we have, when we have them, and how often (Gross, 2002). In our study, we focused specifically on strategies used to alter the intensity and/or duration of positive emotions (i.e., happy, excited, enthused) since many of the stressors present in ICE environments (e.g., altered light-dark patterns, monotony, confinement, social isolation, circadian disruption) are known to significantly degrade positive affect/emotions (Alfano et al. 2018). Positive emotions are also known to robustly influence overall mental health and well-being (Fredrickson, 2000), yet remain understudied in ICE settings.

An additional focus of our study was on the presence of physical symptoms/complaints. Several environmental factors encountered in the Antarctic are known to produce physical changes directly linked with mental health difficulties. For example, long-term exposure to cold temperatures produces changes in thyroid function that can cause fatigue, sluggishness, and changes in urination (Palinkas et al., 2001; Reed et al., 2001), recognized symptoms of low mood/depression (Palinkas et al., 2004; Strange \& Klein, 1974). High altitudes can result in headaches, light-headedness, and cardiopulmonary symptoms including tachycardia and dyspnea (Roth et al., 2002), known features of anxiety and panic (Rodway et. al., 2004; Roth et al., 2002). Physical complaints reported by Antarctic winter-over personnel might therefore serve as 'red flags' for problematic changes in mental health. Findings toward this end are both limited and mixed. For example, among a 24-member Antarctic expedition crew, physical symptoms peaked at mid-winter whereas the highest levels of anxiety occurred subsequently in late winter (Khandelwal et al., 2017). Conversely, in another Antarctic winter-over cohort, thymic reactions (e.g., low mood) increased linearly across mission whereas somatic symptoms (e.g., fatigue, headache, etc.) showed an opposing linear decrease over time (Décamps and Rosnet, 2005). 
Finally, since stress hormones correspond and interact with both psychological and somatic symptoms, we examined corresponding monthly changes in biomarkers of stress collected via saliva sampling. We specifically focused on three indices: cortisol, dehydroepiandrosterone (DHEA), and their ratio. Whereas cortisol is recognized as a primary stress hormone and found to be hypersecreted in depressed individuals (Duval et al., 2006), DHEA is an endogenous steroid that possesses anti-glucocorticoid properties (Kalimi et. al., 1994). The antagonist action of DHEA to cortisol in the brain suggests that measurement of cortisol alone could provide an incomplete picture of the body's stress response (Goodyer et. al., 1998). Thus, we also examined cortisol:DHEA ratios, which have been found to differentiate depressed patients from healthy controls (Michael et al., 2000).

\subsection{Current Study}

The current investigation included personnel stationed at either an inland (South Pole) or coastal (McMurdo) station during a nine-month period including winter-over. We had several specific aims. First, we examined and compared changes in monthly MHCL scores, physical symptoms, and stress biomarker levels both within and between the two stations across mission. We also examined monthly use of five specific cognitive strategies commonly used to regulate (i.e., increase or decrease) positive emotions across the mission in the full sample. Second, we examined the extent to which trait-based psychological measures assessed at baseline served to predict MHCL scores at the end of mission. Finally, we explored whether within-mission severity of physical symptoms, stress biomarkers, and/or emotion regulatory strategies predicted end of mission MHCL scores.

2. Materials and Methods

\subsection{Participants}


A total of 110 participants were enrolled during the nine-month study period (February through October) which included winter months. At McMurdo, $n=88$ personnel were enrolled and at the South Pole, $n=22$ were enrolled. All on-station personnel were eligible to participate. Of the total enrolled sample, participants were predominantly white $(94.5 \%, n=104)$ males $(80 \%, n=88)$ between the ages of 22 and 70 years $(M=37.63, S D=11.95)$. Characteristics of the full sample and at each station are displayed in Table 1. One participant was removed from the study after the baseline assessment due to non-compliance with study procedures (i.e., did not complete measures). Another 16 participants withdrew prior to their scheduled departure from Antarctica. Reasons for withdrawal included emergency medical/behavioral evacuation $(n$ $=7$ ), premature termination of employment contract $(n=2)$, work schedule conflicts $(n=3)$, and unwillingness to continue with study procedures $(n=4)$.

For participants at McMurdo, where departure from the ice is possible during the winter months, personnel differ in the amount of time spent at the station, thus the number of monthly sessions completed varied, ranging from one to seven months. At the South Pole, where smaller crews deploy together, a majority of subjects completed all nine months of assessments. See Table 2 .

\subsection{Environment at the McMurdo Station}

McMurdo Station is a coastal scientific research base located on the southernmost tip of Ross Island, operated by the United States Antarctic Program. It contains the largest community in Antarctica, supporting up to approximately 1,000 personnel during peak summer months (December and January) and approximately 250 people each winter. Given its proximity to the sea, transportation to and from the station is readily available, making evacuation possible even during the coldest months (July-September). Average daily temperature ranges from $-3^{\circ} \mathrm{C}\left(27^{\circ} \mathrm{F}\right)$ 
in the summer months to $-27^{\circ} \mathrm{C}\left(-17^{\circ} \mathrm{F}\right)$ in the winter months. Personnel at McMurdo undergo medical, but not psychological screening prior to arrival at the station.

\subsection{Environment at the South Pole Station}

The Amundsen-Scott South Pole Station is an inland scientific research base located at the South Pole, also operated by the United States Antarctic Program. The South Pole Station is continuously inhabited, supporting approximately 150 personnel during the summer months and 50 personnel during winter-over (mid-February to late October) when evacuation is impossible. Due to its location, the South Pole station has six months of continuous polar night (i.e., no visible sun above the horizon) from March to September, and has a much more extreme climate, with average daily temperature ranging from $-28^{\circ} \mathrm{C}\left(-18.4^{\circ} \mathrm{F}\right)$ in the summer months to $-60^{\circ} \mathrm{C}(-$ $\left.75.6^{\circ} \mathrm{F}\right)$ in the winter months. South Pole personnel undergo psychological screening, including interviews by a mental health professional prior to arriving on station.

\subsection{Measures}

\subsubsection{Baseline Only}

Demographics Questionnaire. Demographic information was collected at baseline including information about sex, age, race/ethnicity, educational level, marital status, prior military service, and previous Antarctic experience.

Anxiety Sensitivity Index-III (ASI-III; Taylor et al., 2007). The ASI-III is an 18-item measure in which respondents indicate the extent to which they are concerned about possible negative consequences of anxiety-related symptoms (e.g., "It scares me when my heart beats rapidly"). Responses are summed to create a total score. A high ASI score has been shown to be a powerful and unique predictor of panic attacks, post-traumatic stress, and fears. The ASI-III 
has strong psychometric properties (Taylor et al., 2007) and full-scale reliability for the current sample was good $(\alpha=.86)$.

Distress Tolerance Scale (DTS; Simons \& Gaher, 2005). Distress tolerance refers to the capacity to experience and withstand negative psychological states. The DTS is a 15 -item selfreport questionnaire examining the degree to which individuals experience negative emotions as intolerable (e.g., "I can't handle feeling distressed or upset.”). The scale has strong psychometric properties (Simons \& Gaher, 2005) and showed excellent reliability in the current sample ( $\alpha=$ $.91)$.

Difficulties in Emotion Regulation Scale (DERS; Gratz \& Roemer, 2004). Emotion regulation deficits have been found to underlie a broad range of affective problems and disorders. The DERS is a multi-faceted measure of emotion regulation that specifically evaluates deficits in the ability to regulate negative emotions. The 36 -item measure yields a total score as well as several subscales. The DERS has been shown to have good test-retest reliability and high internal consistency. In the current sample, the full scale and subscales all showed good reliability $(\alpha$ 's $=.80-.92)$.

\subsubsection{Baseline and Monthly}

The Mental Health Checklist (MHCL). The MHCL is a 23-item, self-report questionnaire created for use in ICE settings (Bower et al., 2019). The original measure was developed in a sequential manner including interviews with subject matter experts (e.g., NASA psychiatrists, a psychologist with polar experience) and comprehensive literature review. The measure requires rating of each item on an 11-point Likert scale from 0 ("never") to 10 ("always"). The MHCL yields three subscale scores: positive adaptation (e.g., in full control, inspired, determined), poor self-regulation (e.g., restless/fidgety, inattentive, sleepy) and anxious 
apprehension (e.g., worried, obsessional/stuck on things). Items were presented in a random order at each time point to prevent practice effects. The measure's psychometric properties were examined in two community samples and reliability for all subscales was found to be good (Bower et al., 2019).

Regulation of Positive Emotions (RPE). In the absence of brief, validated measures for assessing state-based regulation of positive emotional states, we created the 5-item RPE measure for the current study. Items were drawn from the Responses to Positive Affect questionnaire (RPA; Feldman, Joorman \& Johnson, 2008) and the Emotion Regulation Questionnaire (Gross \& John, 2003), two validated dispositional measures of strategies for regulating positive emotions. Five cognitive response-focused strategies used for regulating (i.e., increasing or decreasing intensity) positive emotions were assessed each month, including dampening ("I thought this was too good to be true"), savoring ("I savored the moment/feeling"), reappraisal ("I changed the way I thought about the situation"), self-focused rumination ("I thought about how proud I was of myself") and suppression ("I was careful not to express positive emotions"). Participants indicated the extent to which they used each strategy in response to feeling happy, excited, or enthused during the past week on a 5-point scale ( $0=$ "not at all" to $4=$ "almost all of the time"). Although the RPE does not yield a total score, correlations between each item and total DERS scores at baseline indicate that items associated with maladaptive regulation were positively correlated with total DERS scores (dampening: $r=.31, p=.001$; suppression: $r=.25, p=.008$ ) whereas those associated with adaptive regulation (savoring, self-focused rumination, and reappraisal) did not significantly correlate with the DERS total $(p$ 's $>.1)$.

Physical Symptoms Checklist (PSC). A list of physical symptoms was generated for the current study using the same procedures described for the MHCL. A final list of 29 items 
including common symptoms experiences in extreme environments was created for use in the current study. The PSC was completed monthly during the same session as the MHCL and RPE measures. Each item was rated on a 0 to 10 -point visual analogue scale (similar to MHCL items). Severity of physical symptoms was calculated by totaling scores from all items endorsed at a level greater than 1.

Biomarkers of Stress. All saliva collections were made using synthetic swabs (SalivaBio Oral Swabs, Salimetrics ${ }^{\circledR}$, State College, PA). Participants were instructed to place swabs under their tongue for 3-minutes to saturate and then immediately (within 20 minutes) freeze samples at $-20^{\circ} \mathrm{C}$. Samples were provided immediately after waking, before eating, brushing teeth, or exercising on 3 non-consecutive days during one week of each month. Equal volumes from each day were pooled into a single monthly sample for analysis. Salivary Cortisol and DHEA ELISA kits were used in accordance with the manufacturer's instructions (Salimetrics ${ }^{\circledR}$, State College, PA). We have previously compared the ability of each ELISA kit to detect the salivary analyte of interest with the synthetic oral swab against the 'gold-standard' passive drool. The Salimetrics ${ }^{\circledR}$ oral swab and passive drool methods were highly correlated $\left(\mathrm{r}^{2}=>90 \%\right)$ and spike recovery was $>90 \%$ for all biomarkers measured. Any plates that indicated processing problems were excluded from analyses.

\subsection{Procedures}

Participants were invited via posters, information sessions, and snowball sampling (i.e., research participants informed other crew members about the study) to participate in a study assessing neurobehavioral functioning during the austral Antarctic winter. All participants completed baseline questionnaires upon study enrollment. Additionally, during the first week of participation, individuals provided saliva samples upon waking on 3 non-consecutive days (e.g., 
Monday, Wednesday, Friday). During each subsequent month, participants completed the MHCL, PSC, and RPE, and provided saliva samples on three non-consecutive days of the same week. Saliva was always collecting upon waking, and questionnaires were completed during working hours. All procedures were approved by the National Aeronautics and Space Administration (NASA) and University of Houston Institutional Review Boards. All participants received a T-shirt at the time of enrollment and were entered into a prize draw to win one of two laptop computers after completing the study.

\subsection{Analysis Plan}

All analyses were conducted using SPSS 25.0. Initial exploration of the data showed normality was violated for several measures including the MHCL subscales according to Shapiro-Wilks and Kolmogorov-Smirnov statistics. Parametric analyses were nonetheless conducted since ANOVA/ANCOVA is robust to violations of normality (e.g. Blanca et al., 2017; Levy, 1980). We examined and compared monthly changes in MHCL, RPE, and PSC scores as well as biomarkers of stress across winter using repeated measures analyses of covariance (RMANCOVA) where amount of time on station prior to the baseline assessment was entered as a covariate. Where differences between baseline and end of study scores were detected, paired samples t-tests were used to assess changes from baseline for each subsequent month. For station-based comparisons, we compared participants who provided at least 6 months of data, as we had the largest proportion of McMurdo participants who completed assessments at this time point. The extent to which baseline measures and monthly measures predicted end of study MHCL scores were examined using linear regression models. For the post-hoc t-tests, Bonferroni adjustment and boot-strapping (1000 samples) was used to ensure robust analyses.

\section{Results}




\subsection{Within Mission Changes in Mental Health, Physical Symptoms, and Stress Biomarkers}

\section{$\underline{\text { 3.1.1 Mental Health }}$}

Mean MHCL positive adaptation, poor self-regulation and anxious apprehension score at each time point are presented in Table 3. In the full sample, participants showed a significant decrease in positive adaptation, $F(1,96)=24.48, p<.001\left(\eta^{2}\right.$ partial $\left.=.20\right)$, and significant increase in poor self-regulation, $F(1,96)=15.00, p<.001, \eta_{\text {partial }}^{2}=.14$, from baseline to the end of study. No significant changes were detected for anxious apprehension scores over time, $F(1,96)=1.72$, $p=.19\left(\eta^{2}\right.$ partial $\left.=.02\right)$. Paired samples t-tests comparing baseline scores to subsequent months showed significantly reduced positive adaptation $(p$ 's $<.002)$ at all time points except month 8 , $t(13)=1.52, p=.15$, though the sample size at this time point was reduced $(n=14)$. Compared to baseline, poor self-regulation scores were significantly higher in earlier study months (1 through $5 ; p$ 's $<.02)$ but marginal at later months (6 through $8 ; p$ 's $>.08)$.

To compare symptom trajectories of MHCL scores at the two stations, a mixed ANCOVA was used including data for participants who were on station for 6 months (South Pole $n=19$, McMurdo $n=35$ ) since this time point allowed the most robust comparisons. Controlling for days in Antarctica prior to enrollment, there was a main effect of time for positive adaptation, in which positive adaptation decreased as the study progressed. See Figure 1; $F(4.18,213.37)=6.5, p<.001\left(\eta^{2}\right.$ partial $\left.=.11\right)$. There was also a main effect time for poor selfregulation scores, which increased across the study period. See Figure $2 ; F(3.57,182.25)=2.67$, $p=.04,\left(\eta^{2}\right.$ partial $\left.=.05\right)$. A time by station, $F(1,51)=7.18, p=.01\left(\eta^{2}\right.$ partial $\left.=.12\right)$, interaction was also detected for poor self-regulation scores. Bonferroni adjusted, post-hoc analyses revealed significantly higher poor self-regulation scores at McMurdo compared to the South Pole during month $1(t(68.26)=2.89, p=.04)$, and month $2(t(69.74)=3.77, p<.001)$. There was no 
significant effect of time for anxious apprehension scores, however there was a main effect of station, $F(1,51)=5.48, p=.02\left(\eta^{2}\right.$ partial $\left.=.10\right)$. Post-hoc t-tests indicated that anxious apprehension scores were significantly higher at McMurdo than at South Pole at month 1 ( $p=$ $.04)$ and all subsequent months ( $p$ 's $<.02)$.

\subsubsection{Physical Symptoms}

Severity of physical symptoms in the full sample increased significantly from baseline to the end of study, $F(1,96)=5.11, p=.03\left(\eta^{2}\right.$ partial $\left.=.05\right)$. Paired samples t-tests indicated that severity of physical symptoms was significantly higher at months 1 through 5 and at the end of the study $(p$ 's $<.04)$ but not months 6 through 8 compared to baseline. After controlling for time in Antarctica prior to baseline, a mixed-ANCOVA revealed no significant differences in symptom severity between the two stations.

\subsubsection{Biomarkers of Stress}

Full sample analyses showed no differences between baseline and end of study for cortisol, DHEA, or the cortisol:DHEA ratio (see Table 4 for descriptive statistics for each month; all $p$ 's $>.20$ ). When analyzing participants with a minimum of 6 months of data, cortisol and cortisol:DHEA ratios both showed a within-subjects effect of time (cortisol: $F(6,252)=5.04, \mathrm{p}$ $<.001, \eta^{2}$ partial $=.11$; cortisol:DHEA ratio: $F(6,252)=5.28, \mathrm{p}<.001, \eta^{2}$ partial $\left.=.11\right)$. Bonferroni adjusted post-hoc analyses indicated that at month 4 , cortisol was significantly lower than at baseline, $t(51)=3.05, p=.004$. There was also significant between-subjects effects of station for cortisol, $F(1,42)=6.37, p=.02,\left(\eta^{2}\right.$ partial $\left.=.14\right)$, and cortisol:DHEA ratios, $F(1,42)=4.62, p=$ $.04,\left(\eta^{2}\right.$ partial $\left.=.10\right)$, where both stress biomarkers were higher in McMurdo than South Pole participants.

\subsection{Regulation of Positive Emotion}


Overall endorsement of the five emotion regulation strategies assessed varied in the full sample. Use of suppression and dampening was endorsed significantly less than other strategies $(p$ 's $<.001)$. Savoring was most often endorsed, followed by self-focused rumination, and reappraisal (see Table 3). From baseline to the end of study, use of dampening, $F(1,96)=8.11, p$ $=.005\left(\eta_{\text {partial }}^{2}=.08\right)$, and reappraisal, $F(1,96)=5.74, p=.02\left(\eta_{\text {partial }}^{2}=.06\right)$, strategies

decreased. Use of savoring in response to positive emotions also decreased between baseline and the end of the study, $F(1,96)=13.15, p<.001\left(\eta^{2}\right.$ partial $\left.=.12\right)$. Paired sample t-tests comparing baseline to subsequent months indicated that dampening remained stable and only decreased at the end of the study, $t(97)=2.88, p=.005$. Savoring also remained stable initially, but was significantly reduced during months 5-7 and at the end of the study ( $\left.p^{\prime} s<.03\right)$. Finally, reappraisal in response to positive emotions was lower than baseline for during months $1,2,3,5$, 6 and at the end of the study ( $p$ 's $<.03$ ), but not for months 4,7 and 8 .

\subsection{Trait-based Predictors of End of Mission Mental Health}

Regression analyses were conducted to examine whether end of study MHCL scores were predicted by trait-based emotion dysregulation (DERS total scores). Controlling for baseline positive adaptation and number of days in Antarctica prior to baseline, end of study positive adaptation was significantly lower for participants with higher emotion dysregulation, $F(3,93)=14.38, p<.001, R_{\text {adjusted }}^{2} .30, \beta=-.21, p=.02$. Trait emotion dysregulation did not significantly predict end of study poor self-regulation or anxious apprehension scores. Neither ASI nor DTS significantly predicted end of study MHCL scores.

\subsection{Mission-based Predictors of End of Study Mental Health}

Across mission averages were computed for each of the RPE items, severity of physical symptoms, and total biomarker concentrations. Linear regression models were run separately for 
each item to avoid multi-collinearity. All models controlled for station, time in Antarctica prior to study start and baseline MHCL subscale score. Higher levels of positive adaptation scores at the end of the study were predicted by less within-mission suppression of positive emotions, $F(4,93)=11.77, p<.001 ; R_{\text {adjusted }}^{2} .34, \beta=-.23, p=.007$, and lower total DHEA concentration, $F(4,91)=10.76, p<.001 ; R_{\text {adjusted }}^{2}=.29, \beta=-.21, p=.02$. Conversely, greater poor self-regulation and anxious apprehension scores were predicted by greater within-mission severity of physical symptoms (poor self-regulation: $F(4,93)=32.45, p<.001 ; R^{2}{ }_{\text {adjusted }}=.57, \beta$ $=.39, p<.001 ;$ anxious apprehension: $F(4,93)=20.21, p<.001 ; R_{\text {adjusted }}^{2} .44, \beta=.48, p<$ $.001)$.

\section{Discussion}

As we inch closer to human exploration of the Red Planet, understanding of specific psychological reactions that might threaten a successful Mars mission remains inadequate. Albeit not a perfect analog for space, Antarctica's extreme, inhospitable environment offers an opportunity to systematically investigate the types of emotional changes that emerge in isolated, confined and extreme environments over extended periods of time. The current study examined changes in various types of mental health reactions among personnel at two Antarctic stations across six and nine-month periods. Concurrently, we examined subjective physical symptoms, biomarkers of stress, and the use of different types of regulatory strategies for managing emotional responses toward an enhanced understanding of psychological reactions and changes in this ICE environment.

Among the three MHCL subscales, both positive adaptation and poor self-regulation scores changed significantly across the mission, though patterns of change in these scales were not uniform. For positive adaptation, a continuous linear decrease was observed from baseline to 
the end of the mission. Thus, even as crew members were preparing to return home, positive adaptation scores did not evidence a 'bounce back' effect. Importantly, our positive adaptation scale captured more than just positive affect which, when examined in previous Antarctic studies, has typically not shown similar linear decreases over time (Palinkas \& Suedfeld, 2008; Sandal et al., 2018). Deterioration in the broader range of items that make up this MHCL subscale (e.g., proud, inspired, enthused/spirited, interested/fascinated, perfectionistic) might therefore be viewed as progressive feelings of detachment or indifference over time. Though potentially somewhat normative in ICE settings, emotional reactions are critical for aiding and motivating adaptive coping with the demands of one's immediate environment (Izard, 2009). In this sense, low levels of positive adaptation may increase vulnerability to various types of psychological and situational threats.

For MHCL poor-regulation scores, the greatest increases were observed during the first half of the mission. Scores decreased somewhat in later months, though not back to baseline levels. Multiple aspects of the Antarctic environment are known to negatively affect cognitive processes, thought patterns, and sleep-wake regulation; aspects of functioning assessed by the MHCL poor-self-regulation subscale. Deterioration in these particular domains may be especially pronounced during the coldest, darkest months in the Antarctic (Bhargava et al., 2000; Collet et al., 2015; Reed et al., 2001). Interestingly, higher poor self-regulation scores were observed early in the mission at McMurdo compared to the South Pole station. Considering the harsher, more extreme conditions at the South Pole, and the absence of station-based differences in demographic, military, or prior polar experience, poorer self-regulation scores at McMurdo may reflect the absence of pre-deployment psychological screening at this station. 
By comparison, monthly MHCL anxious apprehension scores did not change significantly over time. Thus, whereas declines in both positive emotion and self-regulatory abilities may be more universal experiences in this ICE setting, changes in anxiety might be shaped more so by individual (e.g., physical symptoms), situational, and/or interactional effects than by broader environmental stressors. The latter thesis is consistent with prior research concluding that elevations in anxiety in polar environments, while often assumed, tend to be the exception rather than the rule (Mocellin et al., 1991). We did observe persistently higher MHCL anxious apprehension scores at McMurdo station where weather elements are less extreme but the population is much larger. A potentially important direction for future work is to examine whether and how reports of anxious apprehension are affected by acute interpersonal stressors.

We also examined changes in the severity of physical symptoms across mission, finding significant increases from baseline to the end of study at both stations. Elevation in physical symptoms during mission also predicted end of study poor self-regulation and anxious apprehension. The trajectory of physical complaints observed in our Antarctic cohort is the opposite pattern found by Décamps and Rosnet (2005), where somatic symptoms among 27 personnel the Dumont-d'Urville station decreased in a linear fashion across a 50-week mission. However, important differences in the latter study include assessment by a physician (rather than self-report), a narrower range of physical symptoms (including a greater emphasis on sleeprelated problems), and fewer assessment points. Together, these findings suggest frequency of assessment, the range of symptoms evaluated, and informant to be important considerations for assessing the contribution of physical symptoms to mental health outcomes in ICE environments. Monthly levels of cortisol and cortisol:DHEA ratios were higher in McMurdo compared to South Pole participants indicating greater experiences of stress at the coastal station. Again, 
the larger McMurdo population likely influences levels of psychosocial stress; laboratory-based studies incorporating social stress paradigms have routinely been shown to evoke a cortisol response (see Dickerson \& Kemeny, 2004). In conjunction with higher MHCL anxious apprehension scores, findings are suggestive of higher levels of arousal/activation at McMurdo. Cortisol secretion follows a circadian rhythm impacted by daylight (Krieger et al., 1971) with the highest levels observed upon waking in the morning (when our samples were collected). Since the South Pole experiences minimal seasonal variation in light-dark cycles, station-based differences may reflect a blunted cortisol response in South Pole personnel. In a prior study, Palinkas et al. (2007) similarly found lower cortisol levels at the South Pole compared to McMurdo station, consistent with suppression of HPA axis activity via a negative feedback loop aimed at maintaining homeostasis (Gjerstad et al., 2018). Importantly, sleep patterns and the timing and composition of artificial lighting also influence diurnal cortisol patterns and may have contributed to observed station-based differences.

Assessment of within-mission use of regulatory strategies indicated that savoring, reappraisal and self-focused rumination were more often used in response to positive emotions than dampening and suppression. This pattern of responding is generally considered adaptive, as the former strategies are associated with effectively increasing and maintaining positive affect (Feldman et al., 2008; Gross, 2002). Decreased use of suppression over time was also associated with greater end of study positive adaptation scores, aligning with community-based findings showing that, in addition to being cognitively taxing, suppression results in worsened emotional outcomes (Gross \& John, 2003; Gross \& Levenson, 1993). Interestingly, savoring was significantly reduced late in the mission and at the end of the study, when positive adaptation scores were lowest. Savoring includes the use of thoughts and actions that increase the intensity, 
duration, and appreciation of positive experiences, either present or past. Salutogenic effects commonly experienced in polar settings and space exploration, which are known to promote well-being (Palinkas \& Suedfeld, 2008; Ritsher, Kanas, Ihle, \& Saylor, 2007) inherently rely to some degree on savoring one's positive experiences. Over time however, as the novelty of one's surroundings and experience lessens, savoring may also diminish. This may be especially relevant for a Mars mission, since many of the previously-reported salutogenic experiences of space flight (e.g., viewing earth from space) will be limited or unavailable.

Since trait-based psychological measures are often used as part of selection procedures, we also explored whether several trait-based constructs assessed at baseline predicted MHCL scores at the end of the study. In a previous study of the current sample, baseline DERS scores were significantly negatively associated with baseline MHCL positive adaptation scores (Bower et al., 2019). Here, controlling for baseline positive adaptation scores, higher baseline DERS scores predicted less positive adaptation at the end of the study. Although the DERS scale focuses on difficulties regulating negative emotional states, scores on this measure have been shown to correlate with difficulty regulating positive emotions as well (Weiss et al., 2015). Further, while it may seem surprising that DERS scores did not predict end of study poor selfregulation scores, items on this MHCL scale assesses regulation of thoughts, behaviors, cognitive processes, and sleep-wake patterns rather than just negative emotions.

Neither DTS nor ASI scores predicted any MHCL scores at the end of the study. There are a few possible reasons for non-significant relationships. Distress tolerance includes one's evaluation and expectation of their ability to experience and endure negative emotional states (Simons \& Gaher, 2005), whereas anxiety sensitivity refers to fear of anxiety-related symptoms based on beliefs that these sensations have harmful consequences (Reiss \& McNally 1985). 
Hence, there are clear conceptual similarities between these constructs. Individuals with low distress tolerance and/or high anxiety sensitivity may be unlikely, in general, to volunteer for a winter-over stay in the Antarctic. Also, while the DTS and ASI possess strong psychometric properties and have been shown to forecast the development of psychiatric problems and disorders (e.g., Grisham et al., 2018; Schmidt, Zvolensky \& Maner, 2006), much of this work has been conducted among clinical or at-risk samples and findings cannot be generalized to groups who self-select for extreme environmental experiences (e.g. polar missions, space flight). In ICE environments, 'meta-cognitive' constructs such as distress tolerance and anxiety sensitivity may be less consequential for mission-based functioning than the actual coping/regulatory strategies utilized (Smith et al., 2017). Consistent with this thesis, our data showed during-mission use of suppression to forecast positive adaptation scores at the end of the mission.

It is somewhat difficult to synthesize the current set of findings with those from previous studies due to wide variability in measures and constructs examined and assessment timing/protocols. One point that bears mentioning however, is that we did not find support for a 'third-quarter effect' reported in some previous studies (e.g., Palinkas \& Browner, 1995; Stuster et al., 2000). Bechtel \& Berning (1991) first described this phenomenon as a low point in morale and mood occurring just after mission midpoint based on awareness that while half of the mission is complete, an equally long period lies ahead. The fact that a third-quarter effect has been inconsistently observed in both polar and space flight research implies that, rather than a reliably-observable phenomenon, multiple factors moderate temporal trajectories of symptoms (e.g., assessment protocols, measure selection, sample characteristics). In fact, the multifaceted nature of ICE environments together with the complexity of the human psyche might render any 
universal, stage-specific model of adaption unlikely. In our study, the patterns of change observed across various monthly measures and markers of stress failed to reveal any one period as uniquely challenging. Future research examining changes in mental health risk based on multi-factorial approaches are therefore likely to be most useful for informing LDSE.

Our study has both strengths and weaknesses. Data collection at two different stations with both shared and unique characteristics offers insight into potential contextual factors that shape psychological risk. Our inclusion of a baseline evaluation along with regular monthly assessments allowed for detection of specific patterns of change over time. However, we did not systematically assess more fluid aspects of the environment also likely to impact mental and physical health including specific station duties, interpersonal conflicts, communication with family members, physical activity/exercise, and alcohol use. Total cortisol and DHEA concentrations were derived from saliva collection upon awakening only, prohibiting insight into the diurnal pattern of these biomarkers. We did not examine the role of sleep patterns or lightdark cycles in this study, both of which have strong implications for emotional health in the Antarctic. Finally, the more transient nature of personnel at the McMurdo station resulted in a smaller than expected number of participants at this station with more 6 months of data, limiting comparisons with the South Pole station.

\subsection{Conclusion}

Our study provides new and interesting findings regarding mental health changes at two Antarctic stations with potential implications for LDSE. In all subjects, positive adaptation scores progressively decreased across the study, suggestive of increasing feelings of detachment and/or indifference over time. Conversely, poor self-regulation scores increased across the study and were predicted by co-occurring increases in the severity of physical symptoms. One 
particularly novel aspect of our study was the assessment of within-mission use of strategies for regulating positive emotion. These data suggest that greater expression of positive emotions and savoring positive experiences may provide a buffer against typical decreases in positive adaptation that occur over long periods in ICE environments. Interventions and/or counter measures directed at sustaining and enhancing positive emotions across extended missions may therefore be useful tool for reducing psychological risk.

\section{Declaration of Conflicting Interests}

The author(s) declared no potential conflicts of interest with respect to the research, authorship, and/or publication of this article.

\section{Funding}

This work was supported by a grant from the National Aeronautics and Space Administration (\#NNX15AC13G) awarded to the first and last authors. 


\section{References}

Alfano, C. A., Bower, J. L., Cowie, J., Lau, S., \& Simpson, R. J. (2018). Long-duration space exploration and emotional health: Recommendations for conceptualizing and evaluating risk. Acta Astronautica, 142, 289-299.

Bechtel, R. B., \& Berning, A. (1991). The Third-Quarter Phenomenon: Do People Experience Discomfort After Stress Has Passed? Paper presented at the From Antarctica to Outer Space, New York, NY.

Bhargava, R., Mukerji, S., \& Sachdeva, U. (2000). Psychological impact of the Antarctic winter on Indian expeditioners. Environ Behav, 32(1), 111-127.

Blanca, M.J., Alarcón, R., Arnau, J., Bono, R., \& Bendayan, R. (2017). Non-normal data: Is ANOVA still a valid option? Psicothema, 29, 552-557.

Bower, J. L., Laughlin, M. S., Connaboy, C., Simpson, R. J., \& Alfano, C. A. (2019). Factor structure and validation of the mental health checklist (MHCL) for use in isolated, confined and extreme environments. Acta Astronautica, 161, 405-414. doi:https://doi.org/10.1016/j.actaastro.2019.03.007

Cazes, G., Rivolier, J., Taylor, A. J., \& McCormick, I. A. (1989). The quantitative and qualitative use of the Adaptability Questionnaire (ADQ). Arctic Med Res, 48(4), 185-194.

Collet, G., Mairesse, O., Cortoos, A., Tellez, H. F., Neyt, X., Peigneux, P., MacdonaldNethercott, E., Ducrot, Y., \& Pattyn, N. (2015). Altitude and seasonality impact on sleep in Antarctica. Aerosp Med Hum Perform, 86(4), 392-396.

Décamps, G., \& Rosnet, E. (2005). A longitudinal assessment of psychological adaptation during a winter-over in Antarctica. Environment and Behavior, 37(3), 418-435. 
Dickerson, S. S., \& Kemeny, M. E. (2004). Acute stressors and cortisol responses: a theoretical integration and synthesis of laboratory research. Psychological Bulletin, 130(3), 355.

Duval, F., Mokrani, M. C., Monreal-Ortiz, J. A., Fattah, S., Champeval, C., Schulz, P., \& Macher, J. P. (2006). Cortisol hypersecretion in unipolar major depression with melancholic and psychotic features: dopaminergic, noradrenergic and thyroid correlates. Psychoneuroendocrinology, 31(7), 876-888. doi:10.1016/j.psyneuen.2006.04.003

Ehmann, B., Altbäcker, A., \& Balázs, L. (2018). Emotionality in isolated, confined and extreme (ICE) environments: Content analysis of diaries of Antarctic Winteroverers. Journal of Environmental Psychology, 60, 112-115.

Feldman, G. C., Joormann, J., \& Johnson, S. L. (2008). Responses to positive affect: A selfreport measure of rumination and dampening. Cognit Ther Res, 32(4), 507-525.

Gjerstad, J. K., Lightman, S. L., \& Spiga, F. (2018). Role of glucocorticoid negative feedback in the regulation of HPA axis pulsatility. Stress, 21(5), 403-416.

Goodyer, I. M., Herbert, J., \& Altham, P. M. (1998). Adrenal steroid secretion and major depression in 8- to 16-year-olds, III. Influence of cortisol/DHEA ratio at presentation on subsequent rates of disappointing life events and persistent major depression. Psychol Med, 28(2), 265-273.

Gratz, K. L., \& Roemer, L. (2004). Multidimensional assessment of emotion regulation and dysregulation: Development, factor structure, and initial validation of the difficulties in emotion regulation scale. Journal of Psychopathology and Behavioral Assessment, 26(1), $41-54$. 
Grisham, J.R., Roberts, L., Cerea, S., Isemann, S., Svehla, J., \& Norberg, M.M. (2018). The role of distress tolerance, anxiety sensitivity, and intolerance of uncertainty in predicting hoarding symptoms in a clinical sample. Psychiatry Research, 267, 94-101.

Gross, J. J. (2002). Emotion regulation: Affective, cognitive, and social consequences. Psychophysiology, 39(3), 281-291.

Gross, J. J., \& John, O. P. (2003). Individual differences in two emotion regulation processes: implications for affect, relationships, and well-being. J Pers Soc Psychol, 85(2), 348-362.

Gross, J. J., \& Levenson, R. W. (1993). Emotional suppression: physiology, self-report, and expressive behavior. J Pers Soc Psychol, 64(6), 970-986.

Gunderson, E. K. E. (1966). Adaptation to Extreme Environments: Prediction of Performance. San Diego, CA: PN.

Gushin, V. I., Kholin, S. F., \& Ivanovsky, Y. R. (1993). Soviet psychophysiological investigations of simulated isolation: some results and prospects. Adv Space Biol Med, 3, 5-14.

Hawkes, C., \& Norris, K. (2017). Time-dependent mood fluctuations in Antarctic personnel: a meta-analysis. Polar Record, 53(5), 534-549.

Institute of Medicine. (2001). Safe Passage: Astronaut Care for Exploration Missions. Washington, DC: The National Academies Press.

Izard, C. E. (2009). Emotion theory and research: highlights, unanswered questions, and emerging issues. Annu Rev Psychol, 60, 1-25.

Kahn, P. M., \& Leon, G. R. (1994). Group climate and individual functioning in an all-women Antarctic expedition team. Environment and Behavior, 26(5), 669-697. 
Kalimi, M., Shafagoj, Y., Loria, R., Padgett, D., \& Regelson, W. (1994). Anti-glucocorticoid effects of dehydroepiandrosterone (DHEA). Mol Cell Biochem, 131(2), 99-104.

Khandelwal, S. K., Bhatia, A., \& Mishra, A. K. (2017). Psychological adaptation of Indian expeditioners during prolonged residence in Antarctica. Indian J Psychiatry, 59(3), 313319.

Krieger D.T., Allen W., Rizzo F., Krieger H.P. (1971) Characterization of the normal temporal pattern of plasma corticosteroid levels. J Clin Endocrinol Metab, 32, 266-284

Levy, K. J. (1980). A Monte Carlo study of analysis of covariance under violations of the assumptions of normality and equal regression slopes. Educational and Psychological Measurement, 40(4), 835-840.

Michael, A., Jenaway, A., Paykel, E. S., \& Herbert, J. (2000). Altered salivary dehydroepiandrosterone levels in major depression in adults. Biol Psychiatry, 48(10), 989-995.

Mocellin, J. S., Suedfeld, P., Bernadelz, J. P., \& Barbarito, M. E. (1991). Levels of anxiety in polar environments. Journal of Environmental Psychology, 11(3), 265-275.

Otto, C. A. (2007). Antarctica: analog for spaceflight. In Presentation to NASA BHP. Houston, TX: Wyle Integrated Science and Engineering Group.

Palinkas, L. A., \& Browner, D. (1995). Effects of prolonged isolation in extreme environments on stress, coping, and depression. Journal of Applied Social Psychology, 25(7), 557-576.

Palinkas, L. A., Glogower, F., Dembert, M., Hansen, K., \& Smullen, R. (2004). Incidence of psychiatric disorders after extended residence in Antarctica. Int J Circumpolar Health, 63(2), 157-168. 
Palinkas, L. A., \& Houseal, M. (2000). Stages of change in mood and behavior during a winter in Antarctica. Environment and Behavior, 32(1), 128-141.

Palinkas, L. A., Reed, H. L., Reedy, K. R., Do, N. V., Case, H. S., \& Finney, N. S. (2001). Circannual pattern of hypothalamic-pituitary-thyroid (HPT) function and mood during extended antarctic residence. Psychoneuroendocrinology, 26(4), 421-431.

Palinkas, L. A., Reedy, K. R., Shepanek, M., Smith, M., Anghel, M., Steel, G. D., Reeves, D., Case, H. S., Do, N. H., \& Reed, H. L. (2007). Environmental influences on hypothalamic-pituitary-thyroid function and behavior in Antarctica. Physiol Behav, 92(5), 790-799.

Palinkas, L. A., \& Suedfeld, P. (2008). Psychological effects of polar expeditions. Lancet, 371(9607), 153-163.

Reed, H. L., Reedy, K. R., Palinkas, L. A., Van Do, N., Finney, N. S., Case, H. S., LeMar, H. J., \& Thomas, J. (2001). Impairment in cognitive and exercise performance during prolonged antarctic residence: effect of thyroxine supplementation in the polar triiodothyronine syndrome. J Clin Endocrinol Metab, 86(1), 110-116.

Reiss, S. \& McNally, R.J. (1985). Expectancy model of fear. In: Reiss S, Bootzin RR, editors. Theoretical issues in behavior therapy. San Diego, CA: Academic Press; pp. 107121.

Ritsher, J. B., Kanas, N. A., Ihle, E. C., \& Saylor, S. A. (2007). Psychological adaptation and salutogenesis in space: Lessons from a series of studies. Acta Astronautica, 60(4), 336340. 
Rodway, G. W., Hoffman, L. A., \& Sanders, M. H. (2004). High-altitude-related disorders--Part II: prevention, special populations, and chronic medical conditions. Heart Lung, 33(1), 312.

Roth, W. T., Gomolla, A., Meuret, A. E., Alpers, G. W., Handke, E. M., \& Wilhelm, F. H. (2002). High altitudes, anxiety, and panic attacks: is there a relationship? Depress Anxiety, 16(2), 51-58.

Sandal, G. M., van deVijver, F. J. R., \& Smith, N. (2018). Psychological hibernation in Antarctica. Front Psychol, 9, 2235.

Schmidt, N.B., Zvolensky, M.J. \& Maner, J.K. (2006). Anxiety sensitivity: Prospective prediction of panic attacks and Axis I pathology. Journal of Psychiatric Research, 40, 691-699

Simons, J. S., \& Gaher, R. M. (2005). The Distress Tolerance Scale: Development and validation of a self-report measure. Motivation and Emotion, 29(2), 83-102.

Slack, K. J., Shea, C., Leveton, L. B., Whitmire, A. M., \& Schmidt, L. L. (2009). Risk of behavioral psychiatric conditions. In J. C. McPhee \& J. B. Charles (Eds.), Human health and performance risks of space exploration missions. (pp. 3-44). Houston, TX: Lyndon B. Johnson Space Center.

Smith, N., Kinnafick, F., \& Saunders, B. (2017). Coping strategies used during an extreme Antarctic expedition. Journal of Human Performance in Extreme Environments, 13(1).

Strange, R., \& Klein, W. (1974). Emotional and social adjustment of recent US winter-over parties in isolated Antarctic stations. In O. G. Edholm \& E. K. E. Gunderson (Eds.), Polar human biology: The proceedings of the SCAR/IUPS/IUBS symposium on human 
biology and medicine in the Antarctic (pp. 410-416). Chicago, IL: Year Book Medical Publications.

Stuster, J., Bachelard, C., \& Suedfeld, P. (2000). The relative importance of behavioral issues during long-duration ICE missions. Aviat Space Environ Med, 71(9 Suppl), A17-25.

Taylor, S., Zvolensky, M. J., Cox, B. J., Deacon, B., Heimberg, R. G., Ledley, D. R., Abramowitz, J. S., Holaway, R. M., Sandin, B., Stewart, S. H., Coles, M., Eng, W., Daly, E. S., Arrindell, W. A., Bouvard, M., \& Cardenas, S. J. (2007). Robust dimensions of anxiety sensitivity: development and initial validation of the Anxiety Sensitivity Index-3. Psychol Assess, 19(2), 176-188.

Weiss, K., Suedfeld, P., Steel, G. D., \& Tanaka, M. (2000). Psychological adjustment during three Japanese Antarctic research expeditions. Environment and Behavior, 32(1), 142156.

Weiss, N. H., Gratz, K. L., \& Lavender, J. M. (2015). Factor structure and initial validation of a multidimensional measure of difficulties in the regulation of positive emotions: The DERS-Positive. Behav Modif, 39(3), 431-453.

Xu, C., Zhu, G., Xue, Q., Zhang, S., Du, G., Xi, Y., \& Palinkas, L. A. (2003). Effect of the Antarctic environment on hormone levels and mood of Chinese expeditioners. International journal of circumpolar health, 62, 255-267. 


\section{Table 1}

Sample Characteristics at each Antarctic Station and the Full Sample

\begin{tabular}{|c|c|c|c|}
\hline & $\begin{array}{l}\text { McMurdo Station } \\
(n=88)\end{array}$ & $\begin{array}{l}\text { South Pole Station } \\
(n=22)\end{array}$ & $\begin{array}{l}\text { Full Sample } \\
(N=110)\end{array}$ \\
\hline & $M(S D) / \%(n)$ & $M(S D) / \%(n)$ & $M(S D) / \%(n)$ \\
\hline Age & $38.8(12.3)$ & $33.1(9.4)$ & $37.6(12.0)$ \\
\hline Gender (Female) & $23.9 \%(21)$ & $4.5 \%(1)$ & $20 \%(22)$ \\
\hline \multicolumn{4}{|l|}{ Race } \\
\hline White & $94.3 \%(83)$ & $95.5 \%(21)$ & $94.5 \%(104)$ \\
\hline Asian & $1.1 \%(1)$ & --- & $.9 \%(1)$ \\
\hline Latino & $2.2 \%(2)$ & --- & $1.8 \%(2)$ \\
\hline Mixed & $1.1 \%(1)$ & --- & $.9 \%(1)$ \\
\hline Other & $1.1 \%(1)$ & --- & $.9 \%(1)$ \\
\hline Missing & --- & $4.5 \%(1)$ & $.9 \%(1)$ \\
\hline \multicolumn{4}{|l|}{ Ethnicity } \\
\hline Hispanic & $4.5 \%(4)$ & --- & $3.6 \%(4)$ \\
\hline Non-Hispanic & $95.5 \%(84)$ & $95.5 \%(21)$ & $95.5 \%(105)$ \\
\hline Missing & --- & $4.5 \%(1)$ & $.9 \%(1)$ \\
\hline \multicolumn{4}{|l|}{ Level of Education } \\
\hline High School & $8.0 \%(7)$ & $4.5 \%(1)$ & $7.3 \%(8)$ \\
\hline Some College & $29.5 \%(26)$ & $22.7 \%(5)$ & $28.2 \%(31)$ \\
\hline Bachelor's degree & $50 \%(44)$ & $45.5 \%(10)$ & $49.1 \%(54)$ \\
\hline Advanced degree & $9.1 \%(8)$ & $22.7 \%(5)$ & $11.8 \%(13)$ \\
\hline Other/Missing & $3.4 \%(3)$ & $4.5 \%(1)$ & $3.6 \%(4)$ \\
\hline Prior Ice Experience (Yes) & $64.8 \%(57)$ & $40.9 \%(9)$ & $60 \%(66)$ \\
\hline Prior Military Experience (Yes) & $20.5 \%(18)$ & $36.4 \%(8)$ & $24 \%(26)$ \\
\hline Days on ice before Baseline & $71.0(73.0)$ & $72.1(40.9)$ & $71.2(67.8)$ \\
\hline
\end{tabular}




\section{Table 2}

Number of Assessments completed at McMurdo and South Pole Stations

\begin{tabular}{lll}
\hline Total Sessions Completed & $\begin{array}{l}\text { McMurdo } \\
n(\% \text { of station })\end{array}$ & $\begin{array}{l}\text { South Pole } \\
n(\% \text { of station })\end{array}$ \\
\hline Baseline only & $6(7 \%)$ & $2(9 \%)$ \\
1 month only & $1(1 \%)$ & $0(0 \%)$ \\
2 months only & $14(16 \%)$ & $0(0 \%)$ \\
3 months only & $13(15 \%)$ & $0(0 \%)$ \\
4 months only & $11(12.5 \%)$ & $0(0 \%)$ \\
5 months only & $8(9 \%)$ & $0(0 \%)$ \\
6 months only & $24(27 \%)$ & $0(0 \%)$ \\
7 months only & $11(12.5 \%)$ & $3(14 \%)$ \\
8 months only & $0(0 \%)$ & $16(72 \%)$ \\
9 months & $0(0 \%)$ & 22 \\
\hline Total & 88 & \\
\hline
\end{tabular}




\section{Table 3}

Means and Standard Deviations for Self-Report Measures at Both Stations and in the Full Sample x Month.

\begin{tabular}{|c|c|c|c|c|c|c|c|c|c|c|}
\hline \multirow{5}{*}{$M(S D)$} & $\begin{array}{l}\text { Baseline } \\
(\mathrm{N}=110)\end{array}$ & $\begin{array}{l}\text { Month } 1 \\
(\mathrm{~N}=103)\end{array}$ & $\begin{array}{l}\text { Month } 2 \\
(\mathrm{~N}=89)\end{array}$ & $\begin{array}{l}\text { Month } 3 \\
(\mathrm{~N}=76)\end{array}$ & $\begin{array}{l}\text { Month } 4 \\
(\mathrm{~N}=64)\end{array}$ & $\begin{array}{l}\text { Month } 5 \\
(\mathrm{~N}=56)\end{array}$ & $\begin{array}{l}\text { Month } 6 \\
(\mathrm{~N}=30)\end{array}$ & $\begin{array}{l}\text { Month } 7 \\
(\mathrm{~N}=19)\end{array}$ & $\begin{array}{l}\text { Month } 8 \\
(\mathrm{~N}=14)\end{array}$ & $\begin{array}{l}\text { End of Study } \\
(\mathrm{N}=98)\end{array}$ \\
\hline & McMurdo & McMurdo & McMurdo & McMurdo & McMurdo & McMurdo & McMurdo & McMurdo & McMurdo & McMurdo \\
\hline & $n=88$ & $n=82$ & $n=68$ & $n=56$ & $n=44$ & $n=36$ & $n=11$ & $n=0$ & $n=0$ & $n=79$ \\
\hline & South Pole & South Pole & South Pole & South Pole & South Pole & South Pole & South Pole & South Pole & South Pole & South Pole \\
\hline & $n=22$ & $n=21$ & $n=21$ & $n=20$ & $n=20$ & $n=20$ & $n=19$ & $n=19$ & $n=14$ & $n=19$ \\
\hline \multicolumn{11}{|c|}{ Mental Health Checklist } \\
\hline \multicolumn{11}{|c|}{ Positive Adaptation } \\
\hline McMurdo & $80.69(16.51)$ & $74.15(15.44)$ & $69.54(15.18)$ & $69.75(18.24)$ & $66.20(18.92)$ & $64.58(20.78)$ & $63.64(24.86)$ & --- & --- & $63.39(18.85)$ \\
\hline South Pole & $72.73(16.31)$ & $68.57(21.06)$ & $68.43(20.82)$ & $63.70(21.87)$ & $64.75(23.82)$ & $62.60(21.37)$ & $64.47(24.64)$ & $60.05(24.75)$ & $66.07(27.81)$ & $63.05(25.25)$ \\
\hline Full Sample & $79.10(16.71)$ & $73.01(16.77)$ & $69.28(16.56)$ & $67.42(19.24)$ & $65.75(20.40)$ & $63.88(20.82)$ & $64.17(24.29)$ & --- & --- & $63.33(20.10)$ \\
\hline \multicolumn{11}{|c|}{ Poor Self-Regulation } \\
\hline McMurdo & $16.16(7.93)$ & $18.93(8.95)$ & $19.16(8.23)$ & $17.75(8.28)$ & $17.95(9.36)$ & $18.61(9.26)$ & $18.64(5.90)$ & --- & --- & $19.96(10.53)$ \\
\hline South Pole & $13.46(4.39)$ & $12.43(3.79)$ & $12.71(3.27)$ & $13.65(4.82)$ & $13.60(4.57)$ & $14.75(5.36)$ & $14.21(6.23)$ & $13.84(5.88)$ & $16.07(6.46)$ & $14.95(6.74)$ \\
\hline Full Sample & $15.62(7.42)$ & $17.60(8.57)$ & $17.64(7.85)$ & $16.67(7.71)$ & $16.59(8.38)$ & $17.23(8.25)$ & $15.83(6.39)$ & --- & --- & $18.99(10.07)$ \\
\hline \multicolumn{11}{|c|}{ Anxious Apprehension } \\
\hline McMurdo & $10.99(6.63)$ & $11.77(5.99)$ & $11.43(6.14)$ & $10.61(5.67)$ & $9.68(5.21)$ & $10.19(5.53)$ & $10.55(5.73)$ & --- & --- & $11.80(7.18)$ \\
\hline South Pole & $8.68(3.85)$ & $6.62(2.38)$ & $7.48(3.08)$ & $6.50(2.97)$ & $6.70(2.41)$ & $7.30(3.25)$ & $6.84(3.06)$ & $6.84(3.42)$ & $7.71(3.34)$ & $7.74(3.71)$ \\
\hline Full Sample & $10.53(6.39)$ & $10.72(5.83)$ & $10.49(5.81)$ & $9.53(5.40)$ & $8.75(4.71)$ & $9.16(5.01)$ & $8.20(4.52)$ & --- & --- & $11.01(6.83)$ \\
\hline \multicolumn{11}{|c|}{ Physical Symptoms Checklist } \\
\hline McMurdo & $33.15(24.16)$ & $39.99(29.16)$ & $36.88(27.81)$ & $34.46(22.07)$ & $35.43(26.78)$ & $33.25(24.55)$ & $27.55(16.27)$ & --- & --- & $39.06(28.25)$ \\
\hline South Pole & $31.23(24.55)$ & $27.24(21.30)$ & $28.95(19.54)$ & $32.45(25.34)$ & $31.85(25.07)$ & $32.60(23.89)$ & $33.26(24.72)$ & $36.21(30.60)$ & $33.57(26.13)$ & $27.21(27.05)$ \\
\hline Full Sample & $32.76(24.14)$ & $37.39(28.12)$ & $35.01(26.21)$ & $33 . .93(22.82)$ & $34.31(26.11)$ & $33.02(24.10)$ & $31.17(21.87)$ & --- & --- & $36.77(28.36)$ \\
\hline
\end{tabular}




\section{State Positive Emotion Regulation}

\begin{tabular}{|c|c|c|c|c|c|c|c|c|c|c|}
\hline Dampening & $1.17(1.16)$ & $1.02(1.03)$ & $.94(1.08)$ & $.82(.86)$ & $.86(.91)$ & $.84(.95)$ & $.60(.62)$ & $.47(.70)$ & $.50(.76)$ & $.77(.89)$ \\
\hline Savoring & $2.56(.97)$ & $2.58(.95)$ & $2.35(.94)$ & $2.33(.99)$ & $2.44(.92)$ & $2.27(1.00)$ & $2.07(1.02)$ & $2.26(.81)$ & $2.57(.94)$ & $2.22(1.15)$ \\
\hline Reappraisal & $1.60(1.09)$ & $1.32(1.06)$ & $1.17(.96)$ & $1.13(.89)$ & $1.19(1.05)$ & $1.00(.85)$ & $.77(.90)$ & $.74(.73)$ & $.79(.70)$ & $1.12(1.01)$ \\
\hline $\begin{array}{l}\text { Self-focused } \\
\text { rumination }\end{array}$ & $2.00(1.01)$ & $2.07(1.05)$ & $1.93(.94)$ & $1.93(1.06)$ & $2.02(1.00)$ & $1.79(1.06)$ & $1.83(1.09)$ & $1.74(.99)$ & $1.71(1.14)$ & $1.83(1.03)$ \\
\hline Suppression & $.77(.96)$ & $.91(1.02)$ & $.92(.76)$ & $.86(.81)$ & $.84(.82)$ & $1.04(.85)$ & $.73(.79)$ & $.79(.71)$ & $.71(.73)$ & $.84(.96)$ \\
\hline
\end{tabular}




\section{Table 4}

Means and Standard Deviations for Stress Biomarkers at Both Stations and in the Full Sample x Month.

\begin{tabular}{|c|c|c|c|c|c|c|c|c|c|c|}
\hline \multirow[b]{3}{*}{ M(SD) } & $\begin{array}{l}\text { Baseline } \\
(\mathrm{N}=106)\end{array}$ & $\begin{array}{l}\text { Month } 1 \\
(\mathrm{~N}=101)\end{array}$ & $\begin{array}{l}\text { Month } 2 \\
(\mathrm{~N}=89)\end{array}$ & $\begin{array}{l}\text { Month } 3 \\
(\mathrm{~N}=71)\end{array}$ & $\begin{array}{l}\text { Month } 4 \\
(\mathrm{~N}=60)\end{array}$ & $\begin{array}{l}\text { Month } 5 \\
(\mathrm{~N}=48)\end{array}$ & $\begin{array}{l}\text { Month } 6 \\
(\mathrm{~N}=\mathbf{2 8})\end{array}$ & $\begin{array}{l}\text { Month } 7 \\
(\mathrm{~N}=19)\end{array}$ & $\begin{array}{l}\text { Month } 8 \\
(\mathrm{~N}=17)\end{array}$ & $\begin{array}{l}\text { End of Study } \\
(\mathrm{N}=95)\end{array}$ \\
\hline & $\begin{array}{l}\text { McMurdo } \\
n=86\end{array}$ & $\begin{array}{l}\text { McMurdo } \\
n=81\end{array}$ & $\begin{array}{l}\text { McMurdo } \\
n=69\end{array}$ & $\begin{array}{l}\text { McMurdo } \\
n=51\end{array}$ & $\begin{array}{l}\text { McMurdo } \\
n=40\end{array}$ & $\begin{array}{l}\text { McMurdo } \\
n=29\end{array}$ & $\begin{array}{l}\text { McMurdo } \\
n=9\end{array}$ & $\begin{array}{l}\text { McMurdo } \\
n=0\end{array}$ & $\begin{array}{l}\text { McMurdo } \\
n=0\end{array}$ & $\begin{array}{l}\text { McMurdo } \\
n=76\end{array}$ \\
\hline & $\begin{array}{l}\text { South Pole } \\
n=20\end{array}$ & $\begin{array}{l}\text { South Pole } \\
n=20\end{array}$ & $\begin{array}{l}\text { South Pole } \\
n=20\end{array}$ & $\begin{array}{l}\text { South Pole } \\
n=20\end{array}$ & $\begin{array}{l}\text { South Pole } \\
n=20\end{array}$ & $\begin{array}{l}\text { South Pole } \\
n=19\end{array}$ & $\begin{array}{l}\text { South Pole } \\
n=19\end{array}$ & $\begin{array}{l}\text { South Pole } \\
n=19\end{array}$ & $\begin{array}{l}\text { South Pole } \\
n=17\end{array}$ & $\begin{array}{l}\text { South Pole } \\
n=19\end{array}$ \\
\hline \multicolumn{11}{|l|}{ Biomarkers } \\
\hline McMurdo & $\begin{array}{l}4016.60 \\
(3131.40)\end{array}$ & $\begin{array}{l}4015.29 \\
(4196.98)\end{array}$ & $\begin{array}{l}4267.74 \\
(4135.79)\end{array}$ & $\begin{array}{l}3941.21 \\
(2676.70)\end{array}$ & $\begin{array}{l}3837.41 \\
(1524.94)\end{array}$ & $\begin{array}{l}4129.40 \\
(1748.37)\end{array}$ & $\begin{array}{l}3768.22 \\
(1496.32)\end{array}$ & --- & --- & $\begin{array}{l}4737.43 \\
(3849.19)\end{array}$ \\
\hline South Pole & $\begin{array}{l}3843.13 \\
(1832.52)\end{array}$ & $\begin{array}{l}2904.66 \\
(1394.87)\end{array}$ & $\begin{array}{l}2647.81 \\
(1294.88)\end{array}$ & $\begin{array}{l}2718.33 \\
(1270.72)\end{array}$ & $\begin{array}{l}2700.92 \\
(1300.73)\end{array}$ & $\begin{array}{l}2691.66 \\
(1444.03)\end{array}$ & $\begin{array}{l}2757.95 \\
(1692.35)\end{array}$ & $\begin{array}{l}2757.95 \\
(1692.35)\end{array}$ & $\begin{array}{l}3508.44 \\
(2478.28)\end{array}$ & $\begin{array}{l}3325.56 \\
(1502.34)\end{array}$ \\
\hline Full Sample & $\begin{array}{l}3983.87 \\
(2924.08)\end{array}$ & $\begin{array}{l}3795.37 \\
(3828.74)\end{array}$ & $\begin{array}{l}3903.71 \\
(3747.23)\end{array}$ & $\begin{array}{l}3597.03 \\
(2494.97)\end{array}$ & $\begin{array}{l}3458.58 \\
(1540.74)\end{array}$ & $\begin{array}{l}3548.19 \\
(1766.01)\end{array}$ & $\begin{array}{l}3082.68 \\
(1674.40)\end{array}$ & --- & --- & $\begin{array}{l}3816.26 \\
(2564.58)\end{array}$ \\
\hline \multicolumn{11}{|l|}{ DHEA } \\
\hline South Pole & $\begin{array}{l}219.46 \\
(78.83)\end{array}$ & $\begin{array}{l}183.02 \\
(81.89)\end{array}$ & $\begin{array}{l}164.59 \\
(67.43)\end{array}$ & $\begin{array}{l}189.66 \\
(1270.72)\end{array}$ & $\begin{array}{l}183.20 \\
(96.19)\end{array}$ & $\begin{array}{l}174.19 \\
(90.69)\end{array}$ & $\begin{array}{l}171.45 \\
(73.30)\end{array}$ & $\begin{array}{l}169.96 \\
(68.37)\end{array}$ & $\begin{array}{l}180.10 \\
(98.37)\end{array}$ & $\begin{array}{l}192.94 \\
(86.70)\end{array}$ \\
\hline Full Sample & $\begin{array}{l}208.76 \\
(132.87)\end{array}$ & $\begin{array}{l}224.06 \\
(216.58)\end{array}$ & $\begin{array}{l}204.78 \\
(133.23)\end{array}$ & $\begin{array}{l}218.43 \\
(144.60)\end{array}$ & $\begin{array}{l}200.85 \\
(132.22)\end{array}$ & $\begin{array}{l}180.46 \\
(108.54)\end{array}$ & $\begin{array}{l}195.04 \\
(120.50)\end{array}$ & --- & --- & $\begin{array}{l}217.87 \\
(138.97)\end{array}$ \\
\hline DHEA/Cortiso & & & & & & & & & & \\
\hline McMurdo & $25.37(20.45)$ & $29.66(53.16)$ & $33.87(67.31)$ & $29.24(45.84)$ & $26.75(21.45)$ & $33.56(28.17)$ & $22.08(15.67)$ & --- & --- & $29.88(43.71)$ \\
\hline
\end{tabular}




\begin{tabular}{|c|c|c|c|c|c|c|c|c|c|c|}
\hline South Pole & $20.54(13.48)$ & $18.25(10.97)$ & $18.33(12.49)$ & $15.87(8.50)$ & $18.73(12.51)$ & 18.91 (14.61) & $17.08(11.43)$ & $20.89(13.02)$ & $22.31(17.24)$ & $21.51(14.65)$ \\
\hline Full Sample & $24.45(19.35)$ & $27.38(47.95)$ & $30.34(59.71)$ & 25.47 (39.47) & $24.08(19.21)$ & $27.64(24.54)$ & $18.69(12.86)$ & --- & --- & 28.19 (39.67) \\
\hline
\end{tabular}

